\title{
Mentoring Pacific Island Students for Conservation Careers
}

\author{
Noelani Puniwai-Ganoot, University of Hawai'i at Mānoa \\ Sharon Ziegler-Chong, Rebecca Ostertag, University of Hawai'i at Hilo \\ Moana Ulu Ching, Conservation International, Hawai'i
}

\begin{abstract}
The Pacific Internship Programs for Exploring Science (PIPES) link undergraduates to environmental careers and mentor the next generation of scientists, educators, and managers for Hawai' $i$ and the Pacific. PIPES uses formal and informal educational frameworks to deepen a sense of kuleana (responsibility) and provide opportunities for engagement in research and conservation practices in a higher education setting. Each summer, 30 to 40 students participate in an intensive, full-time, paid internship program for 10 weeks; 580 undergraduates have completed the program to date. These immersive experiences in science, natural resource management, environmental education, and Hawaiian values help ground interns in the intent of their daily work and provide rich opportunities to develop a deep connection to field sites and organizations.
\end{abstract}

Keywords: internships, kuleana, mentoring, minority student success, Pacific Islanders

doi: 10.18833/spur/1/4/11

Career choices are influenced by many factors, including educational outcome (achievement and attitude), motivation, and instructional quantity and quality (Wang and Staver 2001), as well as knowledge about the type of careers available and the rewards they provide (Lent and Brown 1996). Undergraduates often lack knowledge about viable career options, especially those from underrepresented minorities, and this impacts diversity in the workplace. For example, a recent report (Taylor 2014) studied 191 conservation and preservation organizations,
74 government environmental agencies, and 28 environmental foundations and found that only 16 percent of the boards or staff of these organizations were minorities. This level of staffing diversity is a mismatch with the ethnic and racial makeup of the US population (Haynes, Jacobson, and Wald 2015). At a local level, extreme incongruence between the community and the resource management workforce can lead to feelings of disenfranchisement, as ethnocentric decisions made about the use and conservation of natural resources affect livelihoods (Schelhas 2002).

Resource managers identified underrepresentation of Pacific Islanders in the natural resource management field as a concern in the 1990s. Although the Pacific region is extremely diverse culturally, socially, geographically, and ecologically, the representation of local community members in the academic and agency or organizational workforce is low, especially in leadership roles. Many professionals come from other states, and few reflect the diversity, connection to communities, or 24 percent multiracial makeup of Hawai'i (Krogstad 2015). The values of Hawai'i's rich, vibrant culture are centered on the tenets of natural resource management and sustainability (Kealiikanakaoleohaililani and Giardina 2016), and these values are shared with cultures across the Pacific. The diverse undergraduate population served at universities in Hawai'i grows up closely connected to the environment culturally and socially. However, this student population lacks wide recognition that interest in the environment and their connection to community can be translated into a career if appropriate skills are developed during undergraduate years. 


\section{An Internship Model That Engages the Next Generation of Environmental Leaders}

This article describes the Pacific Internship Programs for Exploring Sciences (University of Hawai'i at Hilo 2018), a suite of three internship programs at the University of Hawai'i at Hilo (UH Hilo). According to data supplied by the Institutional Research Office in fall 2016 UH Hilo had 3,666 undergraduates and was ethnically diverse (34.1 percent were Hawaiian or Pacific Islander, 23.8 percent Asian, 23.7 percent Caucasian, 13.8 percent mixed race, 2.1 percent Hispanic, 1.4 percent African American, and 0.7 percent American Indian and Alaskan Native). In addition, 61.7 percent of the undergraduate student population was female. PIPES interns exceeded this local diversity. Of 580 interns over 24 years, 72 percent self-identified as an underrepresented minority. Additionally, 42 percent of those minority students selfidentified as multiethnic (mixed race). At least 58 percent of the students were female.

PIPES began serving students with the Micronesia and American Sāmoa Student Internship Program (MASSIP) in 1994, and then expanded to serve students who were raised in Hawai' $i$ with the University of Hawai' $i$ Hawaiian Internship Program (UH-HIP) in 1997. Since 2002, UH Hilo has hosted a National Science Foundation Research Experience for Undergraduates (REU) Site Program. Although each program of PIPES has a target focus-MASSIP engages students from Micronesia and American Sāmoa in conservation issues of the Pacific, UH-HIP addresses the management, educational, and outreach conservation needs in Hawai'i, and REU focuses on engaging students in the research process - the programs work collectively to address the challenges of equity in access, participation, and opportunity for underrepresented groups of the islands in the field of conservation. These three programs are recruited and assessed together under the umbrella effort of PIPES. Each summer, a cohort of 30 to 40 students is paired with mentors in an intensive, full-time, 10-week paid internship program. Students engage in internships with faculty or natural resource organization mentors, participate in weekly māhuahua (professional development gatherings) and huaka' $i$ (field trips), and attend the state's annual conservation science conference. At the conclusion of the program, students present their summer experiences in an on-campus forum and complete a final paper (see Table 1). Internship projects are widely diverse and range from implementing outreach programs to outplanting trials and genetic analysis (see Table 2).

To increase the representation of local community members in the academic and agency or organizational workforce, the PIPES model focuses on empowering individuals to succeed in their studies, careers, and communities. The foundations of the program are Hawaiian cultural values, Kolb's (1984) experiential learning model, and best practices of experiential learning (National Society for Experiential Education 2013).

The 10-week program is intentionally structured to provide interns with the opportunity to immerse themselves in a mentored experience in a conservation work setting, to reflect and synthesize their experiences through assignments and discussion, to complete a final product and presentation as the culminating learning achievement of their summer, and to participate in multiple activities that engage them in discussions of their interests, values, and future pathways. Before the summer experience, staff carefully recruit interns using multiple selection criteria to ensure fit with the program, solicit and train mentors with appropriate projects, and plan all aspects of the program with intention. Throughout the summer, staff assess intern learning and experience using formal pre- and postassessments and the BIO REU assessment tool from the Center for the Improvement of Mentored Experiences in Research at the University of Wisconsin-Madison. Staff also evaluate the internship site through an informal site visit to gauge intern and program success. Each successive year interns join a well-networked alumni group. Staff and alumni members share opportunities for employment and scholarships as well as other community possibilities (see Table 1).

PIPES has refined this learning model and structure through program evaluations and focus-group input over the last two decades to support the experience of both intern and mentor. The program is recognized for creation of successful internships for interns and mentors alike, a high participant baccalaureate graduation rate, and high retention in the conservation field. Longitudinal data of the REU-PIPES participants indicate that PIPES has been influential in connecting interns to conservation careers and pursuing further study (see Figure 1). Of 154 alumni since 2002, 80 percent (123) have graduated with a BA or BS degree, and 16 percent (24) have continued their undergraduate coursework. Of those who have graduated with a four-year degree, 65 percent are currently working in conservation, and 43 percent either have earned or are currently pursuing a postbaccalaureate degree, with 14 pursuing or having earned a doctorate and 39 pursuing or having earned a master's degree. A total of 8 alumni are teaching, 5 in the conservation field. There are no longterm data for 7 interns.

\section{Integration of Hawaiian Values into Workforce Training}

The cultural component of the PIPES model is the essential glue that binds the students and staff and enhances the program's reputation and long-term standing. The Hawaiian culture is rooted in family and being a functional part of the community (Vaughan and Ayers 2016). PIPES pillar 
TABLE 1. Elements of the PIPES Program

\begin{tabular}{|c|c|}
\hline Program components & Philosophy \\
\hline $\begin{array}{l}\text { Selection: The selection process occurs over three to four months } \\
\text { and involves a variety of steps: } \\
\text { - Recruit applicants from across the state and region and } \\
\text { through national networks, using in-person and online } \\
\text { informational sessions } \\
\text { - Identify, recruit, and select mentors and projects } \\
\text { - Screen applicants through multiple levels of reviewing } \\
\text { applications, references, and in-person or video interviews } \\
\text { before final selection } \\
\text { - Pair students with appropriate mentors and projects }\end{array}$ & $\begin{array}{l}\text { Selection: Many undergraduate programs choose students based } \\
\text { on their academic achievement. In contrast, although GPA and } \\
\text { coursework are considered as part of the selection process, foremost } \\
\text { among the criteria is a student's sense of kuleana, or responsibility } \\
\text { for being an environmental steward, which roughly translates to } \\
\text { caring for the land (mälama 'áina). } \\
\text { Also selected are students who have had limited exposure to these } \\
\text { ideas but demonstrate through their applications and interviews a } \\
\text { strong potential to feel kuleana toward the environment. }\end{array}$ \\
\hline $\begin{array}{l}\text { Implementation: During the summer program, a variety of } \\
\text { activities occur: } \\
\text { - Mentor training and orientation } \\
\text { - Four-day intern orientation } \\
\text { - Writing assignments that include a personal development plan, } \\
\text { biweekly progress reports, proposal, and final paper written in } \\
\text { four sections } \\
\text { - Māhuahua (professional development) that encompasses } \\
\text { professionalism and time management, introduction to library } \\
\text { resources, read/pair/share, indigenous wisdom and science, } \\
\text { data management, statistics, abstracts, publishing, conferences, } \\
\text { graduate school and career panels, emerging professionals } \\
\text { lunch } \\
\text { - Huaka'i (field trips) that include different ecosystem types } \\
\text { and meetings with natural resource managers and cultural } \\
\text { practitioners } \\
\text { - Attendance at Hawai'i Conservation Conference in Honolulu } \\
\text { - Oral presentations at closing ceremony and celebration }\end{array}$ & $\begin{array}{l}\text { Implementation: Students are exposed to the concept of pono } \\
\text { (righteousness, integrity) in resource management by working with } \\
\text { their mentors and learning about the larger institutional culture of } \\
\text { their agencies or university positions. Through assignments, } \\
\text { reflections, and conversations, students develop independence and } \\
\text { leadership skills. Kuleana is developed by completing assignments } \\
\text { in a timely and professional manner and demonstrating values of } \\
\text { laulima (cooperation) and kokua (helpfulness) during group activities } \\
\text { such as orientation and field trips. } \\
\text { Students' exposure to practitioners during their professional } \\
\text { development activities and field trips and at the statewide conference } \\
\text { allows them to witness others' sense of professional and personal } \\
\text { kuleana and begin to define the kuleana they have in their personal } \\
\text { life path. }\end{array}$ \\
\hline $\begin{array}{l}\text { Assessment and Sustainability: The program undergoes numerous } \\
\text { forms of internal and student evaluation: } \\
\text { - Evaluating by students and mentors } \\
\text { - Synthesizing evaluation results into retooled programming } \\
\text { - Recruiting strategy adjustments } \\
\text { - Longitudinal tracking of alumni through listserve, social media, } \\
\text { and surveys }\end{array}$ & $\begin{array}{l}\text { Assessment and Sustainability: The program performs continuous } \\
\text { formative and summative evaluation of its effectiveness. The sense } \\
\text { of 'ohana (family) continues post-internship through a listserve and } \\
\text { alumni events organized at the Hawai'i Conservation Conference } \\
\text { and when former interns become mentors. Personal achievements of } \\
\text { individuals are shared and examined as group success, demonstrating } \\
\text { that part of the kuleana of working in the natural resource manage- } \\
\text { ment community is giving back to the younger generations. Many } \\
\text { former interns self-identify as stewards undertaking mālama 'äina, } \\
\text { which they practice in their personal and professional lives. }\end{array}$ \\
\hline
\end{tabular}

Note: ${ }^{a}$ There is some variation among the individual internship experiences as some students conduct research and others work on nonresearch activities with their host agencies. However, all interns follow the same programmatic framework. For more information on Hawaiian values, see Kanahele (1986) and Oliveira and Wright (2016).

is kuleana, which can be translated as "doing work that is meaningful and useful to your community," but in reality is a more nuanced concept that incorporates connection to place and reciprocity with the natural world (humans are part of that world). Kuleana is an extremely important value to underrepresented students (Kaomea 2001; Kawelu 2014). In fact, the emphasis on being responsive to family and community needs often limits students' pursuit of higher education and their range of majors and academic careers (Maunakea 2016). Rather than setting up a dichotomy between family and academics, PIPES embraces the kuleana concept, framing the program to meet students' kule$a n a$, or accountability to the community, both human and natural (see Figure 2). Through incorporation of kuleana, the goals of supporting the students and conservation of natural resources are addressed.

In 2013, Ching, a PIPES coordinator, commenced a selfreflective study aimed at increasing the success of the program by instilling a sense of place, and thus kuleana, in the interns. Interns interviewed by Ching explained that their sense of kuleana to the environment was driven by their worldviews and Hawaiian cultural beliefs. Moreover, as they expressed their kuleana to the environment through active stewardship, they also were inspired to maintain their cultural values and practices. This cycle allowed 
TABLE 2. Representative Internship Experiences and Host Sites of PIPES Students

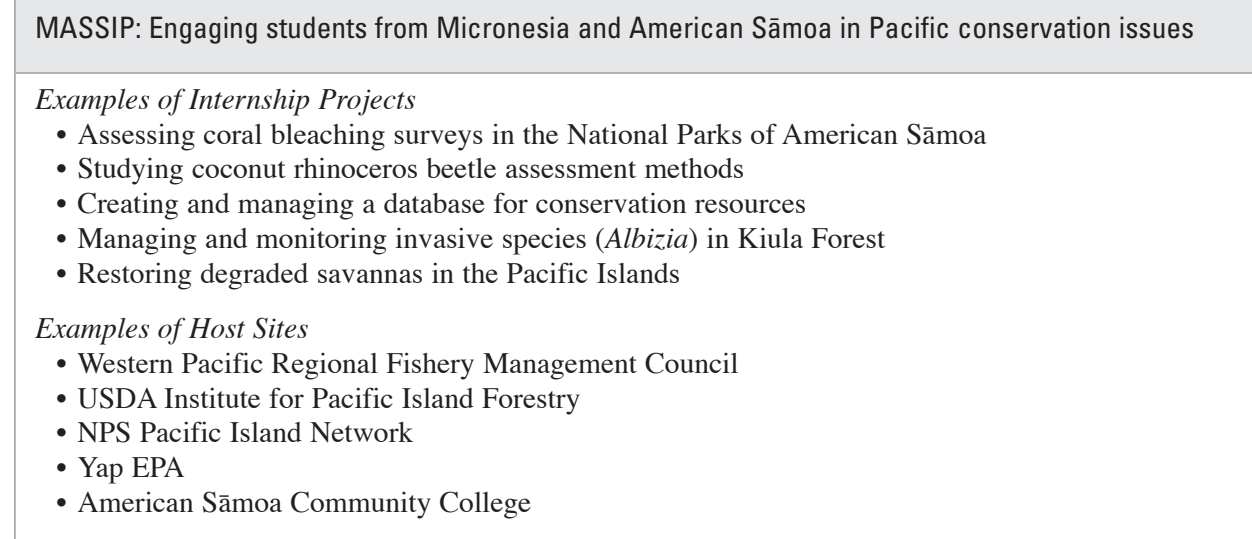

UH-HIP: Addressing the management, educational, and outreach conservation needs of Hawai ${ }^{i} \mathrm{i}$

Examples of Internship Projects

- Water trials on 'A'ali'i outplanting in high-erosion areas

- Management of land-based sediment effects on coral reefs in West Maui

- Rapid 'Ōhi'a Death: Outreach and education

- Diet of Āholehole in Waiāhole Stream

- Geospatial analysis of microbial pollution in Hilo Bay, Hawai' $i$

- Development of a youth education program that links conservation and agriculture

Examples of Host Sites

- Mālama Learning Center

- The Nature Conservancy-Maui Marine

- UH-Hilo Spatial Data Analysis and Visualization Lab

- USDA Institute of Pacific Island Forestry

- Mauna Kea Watershed Alliance, Department of Hawaiian Home Lands

REU: Engaging students in the environmental conservation research process

Examples of Internship Projects

- Nutritional composition of five endemic Hawaiian fruits at 'Alalā release site

- Seasonal and elevation changes in phenotype of the spotted wing drosophila, Drosophila suzukii

- Analysis of captive palila (Loxioides bailleui) foraging behavior

- Population dynamics of shrimp and damselflies in anchialine pool ecosystems

- Facilitation of adaptation in montane plants to changing precipitation along an elevation gradient

Examples of Host Sites

- San Diego Zoo Global-Hawai'i Endangered Bird Conservation Program

- USDA Institute of Pacific Islands Forestry

- UH-Hilo Marine Science, Biology, and Geography Departments

- USDA U.S. Pacific Basin Agricultural Research Center

- UH-Hilo Hawai‘i Cooperative Studies Unit

- USGS Pacific Island Ecosystems Research Center

- State of Hawai ‘i, Division of Aquatic Resources

them to deepen their sense of place (Ching 2015), reinforce shared cultural values, and achieve success professionally and personally.

PIPES staff, many of whom are genealogically rooted in the islands (of native Hawaiian descent) and all of whom have a strong sense of kuleana to conservation and to Hawai' $i$, composed the program mission: to cultivate the next generation of scientists, educators, and managers for Hawai' $\mathrm{i}$ and the Pacific committed to supporting individual and collective success in Hawaiian conservation. It was imperative not only to provide a successful experiential model and develop technical skills and networks but also to ground the program in the values of reciprocity and responsibility in relation to the natural environment of Pacific Island cultures. Other Hawaiian values such as pono (righteousness, integrity), laulima (cooperation), kokua (helpfulness), and 'ohana (family) were also explicitly incorporated into the 
FIGURE 1. Graduation and Employment of REU-PIPES Students, 2002-2017

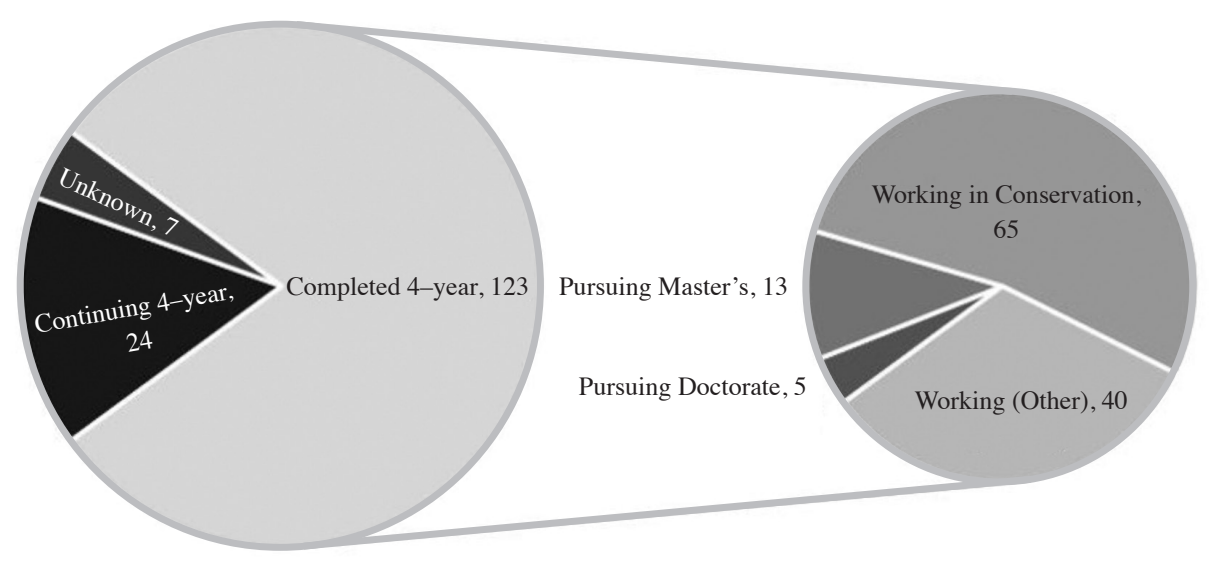

FIGURE 2. Model of Intern Success Based on Developing and Reinforcing a Sense of Place, the Expression of Kuleana, and the Active Role of Stewardship

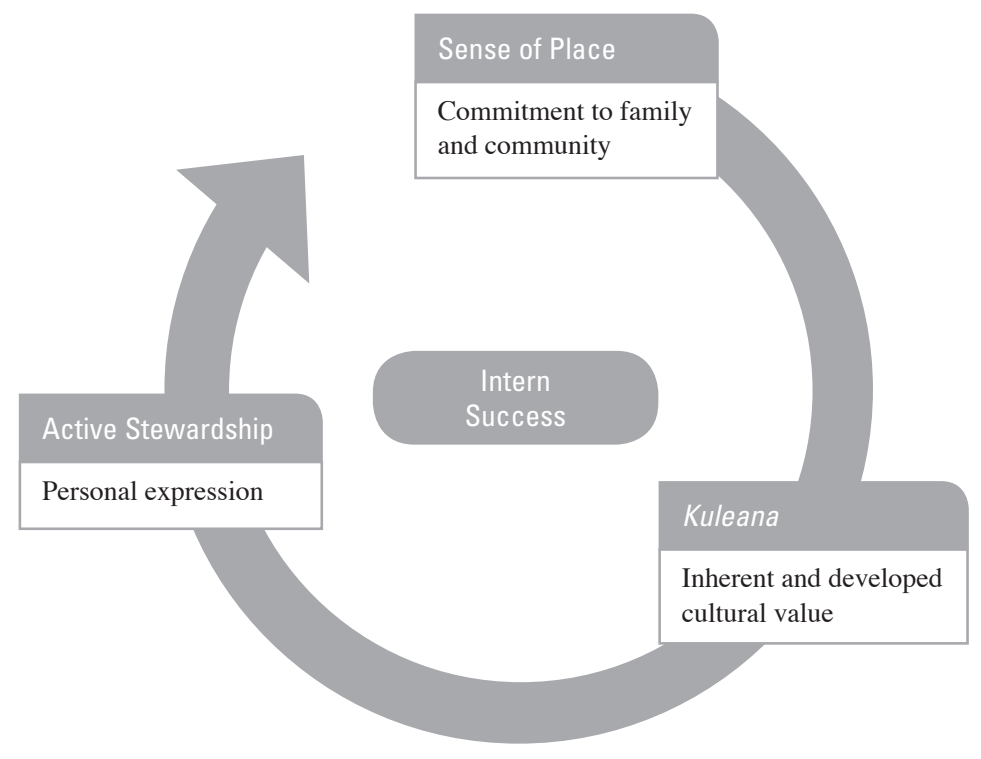

program by intentional cultivation of a sense of place and a deep connection to the natural environment. Students learn about native Hawaiian cultural values through participation in cultural protocols focusing on appropriate etiquette and respect and also stressing the reciprocal nature of acquiring knowledge. These activities support the development of connection to place and include oli (traditional chanting), hula (traditional dance), environmental observation, and traditional farming, fishing, and harvesting activities (Kanahele 1986). The incorporation of cultural aspects into science and natural resource management also is occurring statewide. As an example of this, consider the change in prevalence of three keywords - values, cultural, and community - in a search of presentation abstracts from the 1997, 2007, and 2017 Hawai' ${ }^{\circ}$ Conservation Conferences (see Figure 3). Twenty years ago, presentations on conservation values were absent, and the use of terms such as cultural and community also were limited. In the last 10 years, however, there has been a substantial jump in the use of these three terms, reflecting the growing recognition of local and culturally oriented conservation ideas. Attendance at those same conferences also has come to include more nongovernmental and private organizations over that time period. The authors believe that the combination of technical skills and a firm grounding of self in relation to nature will have 
FIGURE 3. Percentage of Prevalence of the Keywords Values, Cultural, and Community in a Search of Hawai'i Conservation Conference Abstracts Over Three Time Periods

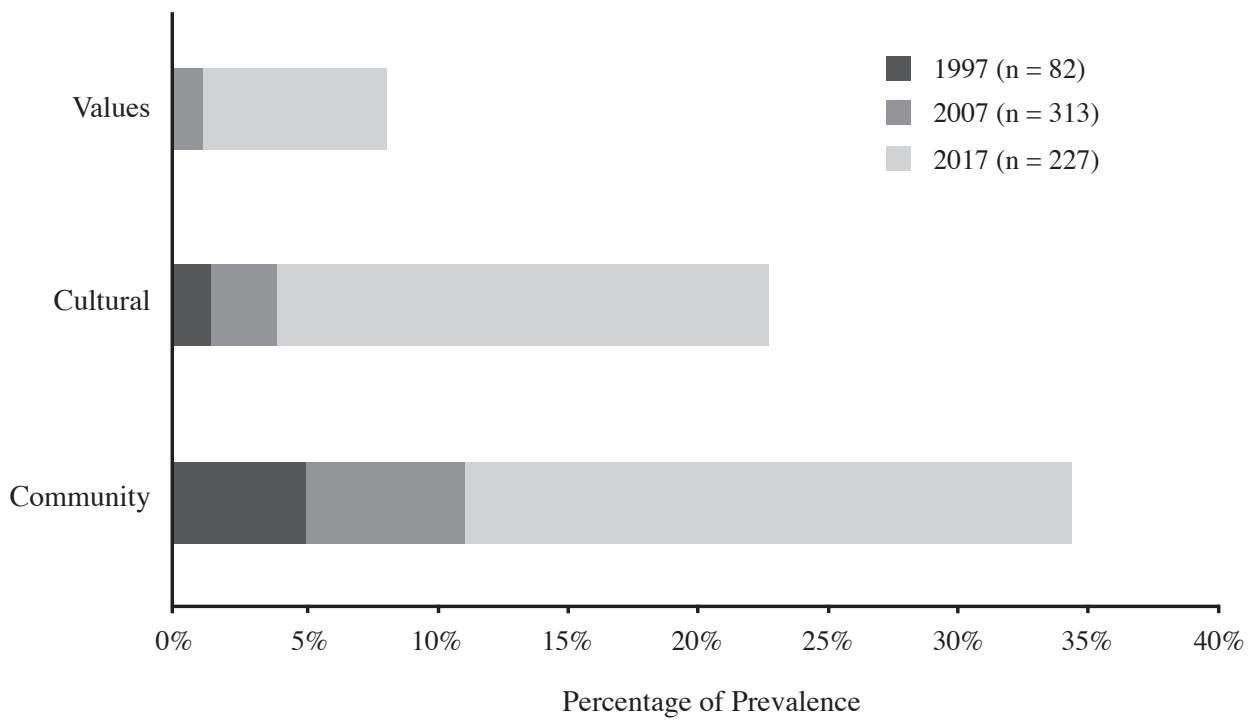

a profound impact on natural resource management and conservation science inquiry in the Pacific.

Kuleana is a complex concept that is a uniquely Hawaiian value, yet it is transportable. It has been adopted in other educational programs outside of Hawai'i (Marlow and Nass-Fukai 2000). What started as a small collaborative effort between a higher educational institution and conservation agencies and organizations to connect local students to issues and careers at home through summer internships has grown into a long-term broader effort to change the face of this field in Hawai' $i$ and throughout the Pacific. PIPES' 25 years of success can provide lessons for other programs with a similar focus.

\section{Success through the Individual and the Collective}

By focusing on kuleana, PIPES can acknowledge that achievement in the program comes in many forms and levels. First, individual success can be defined by a student's personal growth, completion of the internship, or attainment of either graduation or a job. The individual growth witnessed among PIPES participants is supported in the literature of self-authorship and learning. Self-authorship can be defined as the "internal capacity to define one's beliefs, identity and social relations" (Baxter Magolda 2008, 269). In her longitudinal study of college students, she identifies three important elements of self-authorship: trusting one's internal voice, building an internal foundation, and establishing internal commitments to oneself, the world, and relationships. Second, achievement of program success is larger than the sum of individual student successes; its influence is seen in the increased diversity of the natural resource management workforce and, beyond that, in the improvement of Hawai'i's conservation landscapes and the health of the Hawaiian people.

There is evidence of these successes in reflections of alumni on the program's impact as well as the ways in which alumni implement their kuleana in conservation work. These reflections contain keywords like appreciation, kuleana, culture, and community, demonstrating internalization of these concepts. Surveys of the alumni network highlight how interns at many stages in their careers and studies - those who participated years ago and those who have just completed the program-still attribute the strong presence of kuleana in their work to their participation in PIPES (see Figure 4). Across the islands, alumni demonstrate that kuleana through engagement in mālama 'äina (caring for the land) activities. Many lead organizational efforts focused on stewarding island resources and communities through collaborative actions. For others, those community and place relationships grow into graduate student projects, and still others continuously weave their kuleana into agency positions and become leaders respected for their dedication and approaches (see Figure 5).

\section{A General Strategy for Supporting Underrepresented Minority Students}

The takeaway message of the success of PIPES is that incorporating the value system of the student audience and the local culture enhances the internship experience and allows students to become more independent and grounded environmental stewards. The lesson extends beyond the case study of Hawaiian values, because many underrepresented minority students struggle to fit into higher 
FIGURE 4. Reflections of Successful Alumni

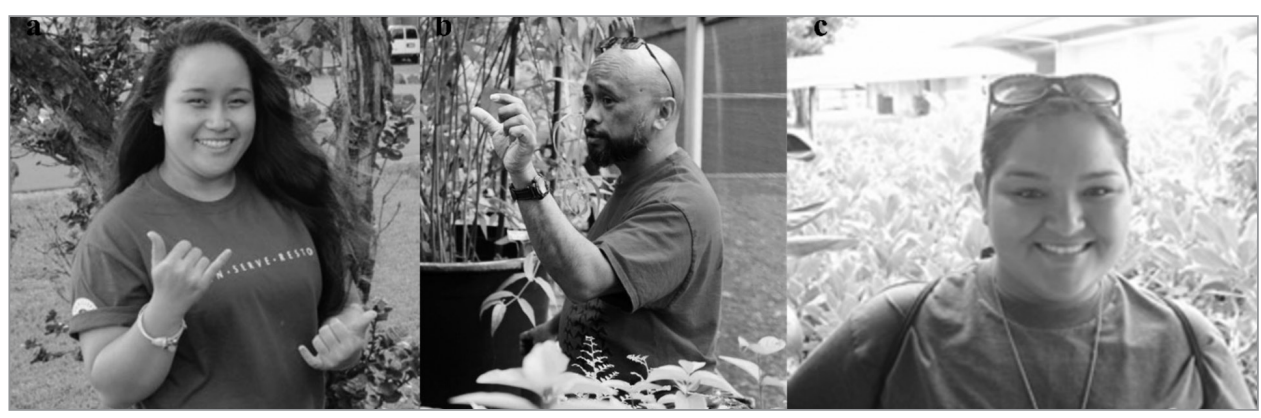

A

B

C

(A) "By participating in PIPES I have gained a deeper sense of appreciation for our environment, for life, and a deeper, more rooted kuleana to this place, our lands, and our environment as a whole." - Candice U'i MinerChing (intern 2016, 2017; graduated 2017 from UH Hilo). (B) "I've been able to learn, experience and internalize conservation to the point that it is a part of my everyday life. These words that ... cannot begin to describe what UH-HIP has done to propel me along my road of self-discovery."-Kahale Pali (intern 2002, 2003; Natural Resources Management Coordinator, Pacific Cooperative Studies Unit). (C) "During PIPES, the importance of culture and community was highlighted and has since inspired me to continue forward in research that benefits my community and my culture."-Chandra Legdesog (intern 2008; graduate student, University of Guam).

\section{FIGURE 5. Highlights of Successful Interns}

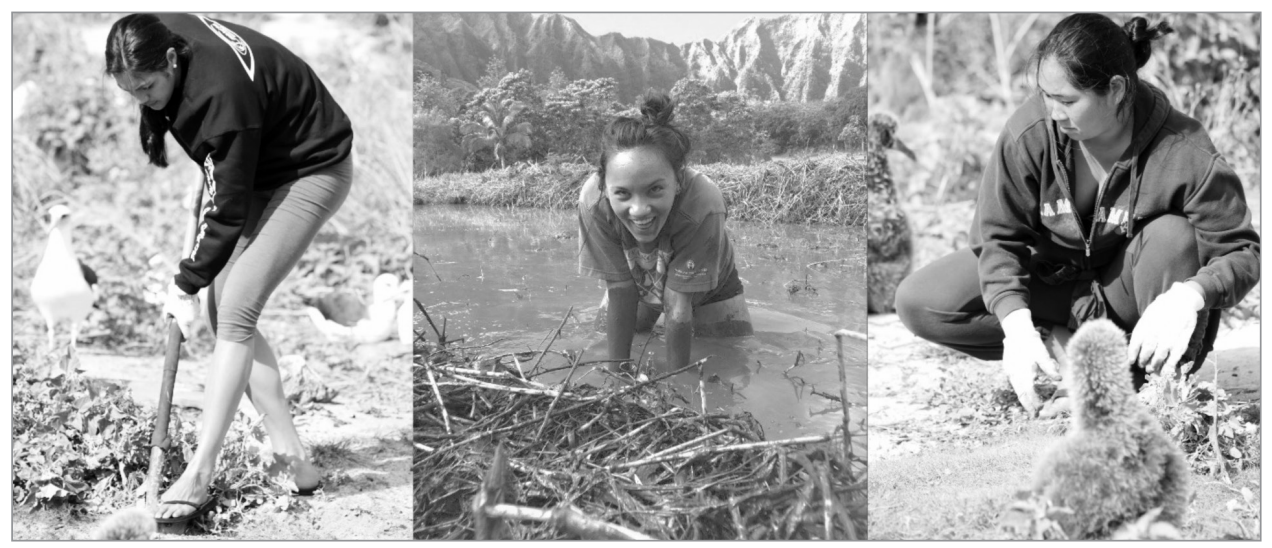

A

B

C

(A) Kau' $\mathrm{i}$ Fu (intern 2011) has returned to her home island of Kaua ' $\mathrm{i}$ and has been influential in restoring community-based management of marine and coastal resources. (B) Emily Cadiz (intern 2012, 2013, 2014) was led by her kuleana to the people and places of Halele'a Kaua' $i$ after her undergraduate internship experiences. She then pursued her master's thesis working in the same communities. (C) Kainana Francisco (intern 2007) has brought her sense of place, kuleana, and commitment to Hawaiian traditions and culture into the USDA Forest Service Institute of Pacific Islands Forestry, influencing local research efforts and partnerships on Hawai'i Island.

education due to misaligned value systems. For example, Vasquez (1990) documents that Hispanic students often value loyalty to family, goals that are achieved communally rather than in isolation or in a competitive manner, and ethnic role models; African American students value oral tradition and a person-centered point of view rather than an object-centered one; and Native American students value holistic learning and the ability to learn something by trial and error in private until mastery, which can then be demonstrated in public. With careful and intentional planning, any of these value systems can be incorporated into the philosophic underpinnings of an undergraduate internship or research program (see Table 1) to foster selfidentity as a professional, which is often a precursor to career attainment (Chemers et al. 2011).

\section{References}

Baxtor Magolda, Marcia B. 2008. "Three Elements of SelfAuthorship." Journal of College Student Development 49: 269284. doi: $10.1353 / \mathrm{csd} .0 .0016$

Chemers, Martin M., Eileen L. Zurbriggen, Moin Syed, Barbara K. Goza, and Steve Bearman. 2011. "The Role of Efficacy and Identity in Science Career Commitment among Underrepresented Minority Students." Journal of Social Issues 67: 469-491. doi: 10.1111/j.1540-4560.2011.01710.x 
Ching, Moana Ulu. 2015. "Pilina Hōnua: Earth Connections." Master's thesis, Lesley University.

Haynes, Nia, Susan K. Jacobson, and Dara M. Wald. 2015. “A Life-Cycle Analysis of Minority Underrepresentation in Natural Resource Fields." Wildlife Society Bulletin 39: 228-238. doi: $10.1002 /$ wsb.525

Institutional Research Office. 2017. Data for Academic Year 2016. Hilo: University of Hawai‘i.

Kanahele, George S. 1986. Ku Kanaka Stand Tall: A Search for Hawaiian Values. Honolulu: University of Hawai'i Press and Waiaha Foundation.

Kaomea, Julie. 2001. "Dilemmas of an Indigenous Academic: A Native Hawaiian Story." Contemporary Issues in Early Childhood 2: 67-82. doi: 10.2304/ciec.2001.2.1.9

Kawelu, Kathleen. 2014. Kuleana and Commitment: Working Toward a Collaborative Hawaiian Archaeology. Honolulu: University of Hawai'i Press.

Kealiikanakaoleohaililani, Kekuhi, and Christian P. Giardina. 2016. "Embracing the Sacred: An Indigenous Framework for Tomorrow's Sustainability Science." Sustainability Science 11: 57-67. doi: 10.1007/s11625-015-0343-3

Kolb, David A. 1984. Experiential Learning: Experience as the Source of Learning and Development. Englewood Cliffs, NJ: Prentice Hall.

Krogstad, Jens M. 2015. "Hawai' $i$ is Home to the Nation's Largest Share of Multiracial Americans." Washington, DC: Pew Research Center. http://pewrsr.ch/1Gf4DYO.

Lent, Robin W., and Steven D. Brown. 1996. "Social Cognitive Approach to Career Development: An Overview." Career Development Quarterly 44: 310-321. doi: 10.1002/j.2161-0045.1996. tb00448.x

Marlow, Michael P., and Jennifer Nass-Fukai. 2000. "Collegiality, Collaboration, and Kuleana: Three Crucial Components for Sustaining Effective School-University Partnerships." Education 121: 188-194.

Maunakea, Summer P. 2016. "Arriving at an 'Āina Aloha Research Framework: What Is Our Kuleana as the Next Generation of 'Ōiwi Scholars?" In Kanaka 'Ōiwi Methodologies: Mo'olelo and Metaphor, ed. Katrina-Ann R. Oliveira and Erin Kahunawaika'ala Wright, 142-159. Honolulu: University of Hawai’i Press. doi: 10.21313/hawaii/9780824855857.003.0009

National Society for Experiential Education. 2013. "Eight Principles of Good Practice for All Experiential Learning Activities." http://www.nsee.org/8-principles

Oliveira, Katrina-Ann R., and Erin Kahunawaika'ala Wright, eds. 2016. Kanaka 'Ōiwi Methodologies: Mo'olelo and Metaphor. Honolulu: University of Hawai`i Press.

Schelhas, John. 2002. "Race, Ethnicity, and Natural Resources in the United States: A Review." Natural Resources Journal 42: 723-763.

Taylor, Dorceta E. 2014. "The State of Diversity in Environmental Organizations." Green 2.0. http://www.diversegreen.org/ the-challenge/

32 Scholarship and Practice of Undergraduate Research
University of Hawai'i at Hilo. 2018. "Pacific Internship Programs for Exploring Sciences (PIPES)." https://hilo.hawaii.edu/ uhintern

Vasquez, James A. 1990. "Teaching to the Distinctive Traits of Minority Students." Clearing House 63: 299-304. doi: 10.1080/00098655.1990.10114113

Vaughan, Mehana B., and Adam L. Ayers. 2016. "Customary Access: Sustaining Local Control of Fishing and Food on Kaua'i's North Shore." Food, Culture \& Society 19: 517-538. doi: 10.1080/15528014.2016.1208339

Wang, Jianjun, and John R. Staver. 2001. "Examining Relationships between Factors of Science Education and Student Career Aspiration." Journal of Educational Research 94: 312-319. doi: 10.1080/00220670109598767

\section{Noelani Puniwai-Ganoot}

University of Hawai'i at Mānoa, npuniwai@hawaii.edu

Noelani Puniwai-Ganoot, assistant professor at the University of Hawai' $i$ at Mānoa, is passionate about cultivating the next generation of students to mālama 'āina (care for the land). She is formerly an intern (1997) and coordinator (2009-2013) in PIPES. Her academic goals are to bring the values of aloha 'aina (love and care of the environment) and ho'oulu lāhui (support for the health of the community) to her research and teaching practices.

Sharon Ziegler-Chong, director of PIPES, has worked in experiential education and partnership programming for more than 30 years. Her passions are developing the individuals and leaders of the next generation as well as facilitating conservation partnerships in the United States and abroad. Ziegler-Chong has worked since 1992 for the University of Hawai' $i$; started PIPES in 1994; and works with colleagues, former interns, and many partners to build and strengthen collaborative conservation efforts through her role as director of many research and community partnerships at the University of Hawai ' $i$ at Hilo.

Rebecca Ostertag, professor of biology, currently directs the tropical conservation biology and environmental science master's program at the University of Hawai'i at Hilo. As a tropical forest ecologist, she works on projects relating to forest dynamics, nutrient cycling, and restoration. Ostertag incorporates the extraordinary biocultural landscapes of Hawai' 'i Island into her teaching and research and has mentored more than two dozen undergraduates in field ecology topics.

Moana Ulu Ching, a senior program manager with Conservation International-Hawai ' $i$, continues the legacy of her 'ohana through education and active participation in the care of the natural environment and connected cultural practices. She is an active advocate of community-driven efforts that support the development of Hawai'i's youth and the preservation of traditional practices that conserve natural resources. Ching is a former PIPES intern (2005 and 2006) and program coordinator (2007-2016). 